\title{
El shock de precios de los productos básicos en Bolivia
}

\section{Gabriel Loza T.}

Banco Central de Bolivia

Gloza@mail.bcb.gov.bo
El shock adverso en los precios de los productos básicos ha recibido escasa atención, si se compara con la que se ha prestado a la crisis financiera reciente. A diferencia de lo señalado por la literatura empírica, la caída reciente de las cotizaciones internacionales muestra que la mayoría de los precios tienden a moverse juntos en las fases expansivas y contractivas del ciclo económico. Los shocks (perturbaciones) permanentes ayudan a explicar la varianza de los precios de exportación de Bolivia. Además, la incorporación a la cartera exportadora de un nuevo sector, como el de la soja, no ha disminuido el riesgo total. Se concluye que en Bolivia la política de diversificación de las exportaciones de productos básicos no ha permitido al país minimizar el riesgo, atenuar los ciclos, disminuir la volatilidad de los precios ni aumentar los ingresos reales de exportación. Se sugiere desarrollar las exportaciones de manufacturas a fin de disminuir la vulnerabilidad ante perturbaciones adversas. 


\section{I}

\section{Introducción}

La reciente crisis internacional y las perturbaciones financieras internacionales han centrado el debate en los flujos de capitales, su elevada volatilidad y el efecto contagio. Sin embargo, la fuerte caída de los precios internacionales de los productos básicos no ha recibido igual atención. Incluso parece haber pasado inadvertido uno de los shocks más fuertes y virulentos en muchos años, que afectó a los precios de los productos primarios y, por ende, a las economías en desarrollo que dependen de las exportaciones de estos bienes.

Debido a que Bolivia no participa activamente del mercado de bonos y acciones internacionales -es decir, es poco significativa la inversión directa en cartera y es baja la movilidad de capitales de corto pla$\mathrm{zo}^{1}-$, y a que depende fuertemente de sus exportaciones de productos básicos, el análisis de los shocks de los precios internacionales de estos últimos resulta muy relevante. El comportamiento de las cotizaciones internacionales de productos primarios muestra en los últimos años una perturbación adversa que ha provocado una fuerte inestabilidad y ha reducido tanto los ingresos de exportación como los ingresos reales bolivianos. Cabe preguntarse si la caída experimentada obedece a trastornos transitorios que tenderían a disiparse o podrían ser enfrentados con medidas de estabilización de los ingresos de exportación, o si, por el contrario, corresponde a trastornos persistentes de naturaleza estructural que exigen medidas de mayor alcance.

Pese al cambio en su política económica a partir de agosto de 1985, Bolivia no ha podido elevar la participación de las exportaciones de manufacturas en sus exportaciones totales. Pero ha logrado diversificar sus exportaciones de productos básicos, a diferencia de 57 países en desarrollo de Africa y América Latina que dependen en más de $50 \%$ de tres productos primarios. Esta situación, desde el punto de vista de la teoría de cartera, debería permitirle disminuir el riesgo si los

$\square$ Este trabajo es parte de una investigación más amplia que el autor está realizando en el Banco Central de Bolivia. Las opiniones aquí vertidas no comprometen a esa institución. El autor agradece a Boris Zambrano por la elaboración de la parte econométrica bajo la supervisión de Oscar Lora y agradece asimismo los aportes y comentarios de Raúl Mendoza, Oscar Lora y Boris Gamarra.

${ }^{1}$ La internacionalización de la economía aumentó en los últimos años con la incursión de la banca extranjera en el sistema financiero nacional. precios de los productos que conforman la canasta exportadora no registran comportamientos en el mismo sentido, es decir, si presentan covarianzas negativas. En la reciente crisis, la caída de los precios afectó a la mayoría de los productos que integran la canasta exportadora boliviana: los precios se movieron en la misma dirección, aumentando por lo tanto el riesgo de cartera.

Situaciones como las descritas tienen fuertes implicaciones de política, puesto que si el riesgo en lugar de disminuir aumenta, si los períodos de declinación coinciden y si los shocks son persistentes, no sería correcto insistir exclusivamente en una política implícita de diversificación de las exportaciones de productos básicos, sino que se requerirían medidas de carácter estructural orientadas a lograr una mayor participación de las exportaciones de manufacturas.

A diferencia de la literatura sobre las crisis financieras, las publicaciones recientes que tratan las fluctuaciones de los precios de los productos básicos son más limitadas. Están el trabajo de Dehn (2000a) sobre los efectos de la incertidumbre y los shocks de los precios de tales productos en el crecimiento y el de Cashin y Patillo (2000) acerca de las perturbaciones de los términos de intercambio en Africa. A su vez, Cashin, Liang y McDermott (1999) analizaron la persistencia de las perturbaciones de los precios de los productos básicos, y Cashin, McDermott y Scott (1999b) el mito del comovimiento de esos precios. No obstante, el trabajo principal sigue siendo el de Reinhart y Wickhan (1994) sobre la persistencia o transitoriedad de los shocks de los precios de los productos básicos.

En este contexto, el objetivo central del presente trabajo es verificar si durante la crisis de los años 1998 y 1999 la diversificación de las exportaciones de productos básicos ha sido una especie de política anticíclica que ha permitido atenuar los efectos negativos de las fuertes caídas de los precios internacionales o, si por el contrario, no ha permitido minimizar el riesgo de cartera de la canasta exportadora ni ha disminuido la vulnerabilidad externa del país.

El objetivo específico es analizar el comportamiento de los precios de los productos básicos de exportación de Bolivia durante la crisis reciente, para identificar las principales características relativas a la índole persistente o transitoria de los shocks, a la 
presencia de comovimientos en el comportamiento cíclico, a la volatilidad de los precios y al riesgo de la cartera de productos básicos de exportación.

El período de análisis basado en series mensuales abarca desde enero de 1992 a septiembre de 2000, y para él se dispone de información sobre la canasta de productos elaborada por el Banco Central de Bolivia sobre la base de diciembre de 1996, de manera que sirva como marco de referencia para analizar la perturbación externa de precios en 1998 y 1999.

Para tal efecto, en la sección II del artículo se pasa revista a la literatura teórica y empírica relativa al comportamiento de los precios de los productos básicos, haciendo hincapié en la tesis de Prebisch (1949) sobre la tendencia al deterioro secular de los términos de intercambio y la volatilidad de los precios de los productos primarios. Luego, en la sección III, se analiza la evolución y composición de las exportaciones de Bolivia en la década de 1990, los índices de precios para productos básicos de que se dispone y el comportamiento de la relación de precios del intercambio. En las secciones IV y V se presenta la evidencia empírica sobre la persistencia o temporalidad de los shocks externos, sobre la volatilidad de los precios de los productos básicos y sobre el riesgo de cartera de la canasta de productos básicos de exportación. Por último, las conclusiones se presentan en la sección VI, junto con algunas recomendaciones de política relativas a la importancia de desarrollar las exportaciones de manufacturas.

\section{II \\ Consideraciones teóricas y empíricas sobre los precios de los productos básicos}

El tema de la declinación de los precios de los productos básicos se introdujo en la literatura económica a partir de las tesis de Prebisch (1949) y Singer (1950), que señalaban que en el largo plazo existía una tendencia secular al deterioro de los términos del intercambio, debido a que los precios de los productos primarios crecían en menor proporción que los de las manufacturas (CEPAL, 1969).

La tesis tuvo inicialmente dos versiones. Según Bielschowsky (1998), la primera, que está expuesta en el llamado "manifiesto latinoamericano" (Prebisch, 1949), señala que en la fase decreciente del ciclo los sindicatos de los países industriales lograban impedir la caída de los precios de los bienes industriales, contrarrestando con creces las ganancias que la periferia obtenía con el auge cíclico de los bienes primarios. La segunda versión, expuesta por Prebisch (1952) y que posteriormente desarrollaría Lewis (1960), está relacionada con el exceso de mano de obra en la agricultura de la periferia, que no es transferible a los países desarrollados, lo que deprime el precio de los productos de dicho sector. Ambas versiones en realidad se centran en la rigidez relativa de los mercados de trabajo en los países desarrollados y en desarrollo, como lo demuestra Ros (1998).

Una tercera versión, más elegante y basada en Singer (1950), se centraba en las diferencias de la elas- ticidad-precio de la demanda y la elasticidad-ingreso que enfrentaban los productos básicos, las que eran menores a uno. Sin embargo, la versión más amplia enunciada en CEPAL (1969) postula que si los precios reflejaran estrictamente el menor costo que el progreso técnico trae consigo, los precios industriales disminuirían más que los primarios, porque la productividad en la industria es mayor que en las actividades primarias. Como el progreso técnico no se distribuye uniformemente entre los países, la periferia tiende a transferir parte del fruto del progreso técnico a los centros, en tanto que éstos retienen el suyo propio.

Para la teoría pura del comercio internacional, el tema del deterioro de los términos de intercambio fue considerado un problema técnico esotérico, y en el ámbito político se le miró como un tema con alta carga emocional. Junto al deterioro secular de los precios primarios se hallaba el tema de la inestabilidad de los precios de exportación, aunque según Krueger (1984) éstos son dos tópicos estrictamente separados. La literatura empírica redujo la tesis a nivel de hipótesis ${ }^{2}$ al estimar que la evidencia no era concluyente. La base

\footnotetext{
${ }^{2}$ Sobre este punto, y respecto a las menciones siguientes de Spraos y Michaely en este mismo párrafo, véanse las referencias en Borensztein, Khan y otros (1994).
} 
empírica de Prebisch abarcaba el período de 1870 a 1930 y utilizaba precios de exportación de Inglaterra, considerados como precios de manufacturas, y precios de importación, considerados como precios de productos primarios. Spraos, en un trabajo de 1980, concluyó que probablemente hubo un deterioro secular en el período abarcado por Prebisch, pero que más allá de la posguerra es muy dudoso que se haya dado ese deterioro. Incluso Michaely señaló en 1982 que para el período 1952-1973 los precios de exportación de los países pobres crecieron más rápidamente que los de los países ricos.

Sprout (1992) señala que hay una descorazonadora contradicción entre los resultados de los esfuerzos para probar la tesis y concluye, con un criterio cuantitativo, que de los más importantes estudios, un tercio confirma la hipótesis de Prebisch y un cuarto la niega.

El tema de la inestabilidad de los precios también fue visto como bastante contradictorio y no concluyente y se consideró que incluso en el corto plazo dicha inestabilidad habría sido exagerada (Krueger, 1984, p. 595).

Las políticas que el FMI recomendaba frente a desequilibrios en la balanza de pagos derivados de caídas en los ingresos de exportación fueron básicamente dos: el financiamiento compensatorio de emergencia, establecido en 1964, y los fondos de estabilización de precios para productos específicos. Estas medidas se sustentaban en un enfoque de desequilibrios transitorios.

A mediados del decenio de 1990 retornó el énfasis en la persistencia de los shocks en los precios de los productos básicos, con el trabajo empírico de Reinhart y Wickham (1994), quienes, basándose en métodos de descomposición de series de tiempo entre tendencia secular y cíclica, encuentran las siguientes regularidades para el período 1957-1993:

- La debilidad de los precios reales de los productos básicos es de naturaleza secular, persistente y no se debe a desviaciones temporales respecto de la tendencia.

- La importancia relativa de los shocks permanentes en los precios varía según el grupo de productos considerados, siendo menor en los metales y mayor en las bebidas (café, té).

- Las características del ciclo varían según los productos, siendo menos persistentes en los metales y más persistentes en las bebidas.

- Los precios medios son marcadamente bajos y hay un incremento sostenido de la varianza de los precios de productos primarios. El coeficiente de variación aumenta bruscamente y los precios se tornan más volátiles en torno a la media.

Las recomendaciones del trabajo citado hicieron hincapié en la necesidad de adoptar políticas estructurales como la de diversificación de las exportaciones, dado que la debilidad era de naturaleza secular; pero debido a la elevada volatilidad de los precios, también consideraron aconsejable utilizar estrategias de cobertura y fondos de estabilización.

Sin embargo, sólo a fines de los años noventa la literatura empírica recobra el interés por el tema de los productos básicos. Cashin, Liang y McDermott (1999) se basan en la estimación de la mediana insesgada, que es superior al test de la raíz unitaria para determinar la persistencia de perturbaciones en los precios de los productos básicos, y utiliza información mensual sobre 60 productos básicos para el período 1957-1998. Ese trabajo encuentra que las perturbaciones de los precios de la mayoría de los productos básicos son típicamente de larga duración y que la variabilidad de su persistencia es bastante amplia. Asimismo, halla diferencias entre grupos de productos, siendo más persistentes en los metales que en las maderas. En consecuencia, concluye que es incorrecto ver los shocks de los precios de los productos primarios como un fenómeno temporal: al ser ellos persistentes, es probable que una perturbación adversa de precios deprima a éstos por un largo tiempo. De lo anterior se desprende que medidas como el financiamiento compensatorio y los fondos de estabilización probablemente no sean eficaces y que la suavización del consumo no llegue a ser sostenible.

En su análisis de la duración y magnitud de los ciclos de los precios de los productos básicos, Cashin, McDermott y Scott (1999a) encuentran, para el período 1957-1999 y sobre la base de series mensuales para 36 productos, lo siguiente:

- Existe una asimetría en los ciclos de los precios caracterizada por una fase de declinación que dura por lo menos un año más que la fase de auge.

- La magnitud de la caída de los precios en la fase de declinación es mayor que el alza de los precios en la fase de recuperación del ciclo, mientras que la tasa de variación de los precios en la fase de auge es más rápida que en la fase de declinación.

- Hay poca evidencia de una forma consistente en el ciclo de los precios.

- No hay una relación de dependencia entre la duración de la fase de declinación y la de la fase de auge. El hecho de que grandes movimientos adversos en los precios continúen por un largo tiem- 
po no significa que haya mayor probabilidad de que la fase de declinación vaya a terminar con el inicio de la fase de recuperación.

Un reciente trabajo de Cashin, McDermott y Scott (1999b), que abarca el período 1957-1999 y utiliza información mensual, halla evidencia empírica de que los precios de los productos básicos no se mueven juntos, a menos que se trate de productos directamente relacionados (que sean del mismo sector o rama). Definiendo los comovimientos como concordancia —es decir, la proporción de tiempo en que los precios de dos productos básicos están en el mismo período de auge o declinación- no encuentra evidencia de que esos precios se muevan juntos, excepto para el oro y el petróleo. Las conclusiones de política que pueden extraerse son importantes, puesto que si los precios de los productos básicos se mueven juntos, para disminuir el riesgo habría que diversificar recurriendo a exportaciones de manufacturas, en las cuales se podrían no tener ventajas comparativas. Por el contrario, de no existir comovimientos se podrían diversificar las propias exportaciones de productos básicos.

Después de muchos años, el tema de los shocks de la relación de precios del intercambio ha cobrado un nuevo dinamismo. Cashin y Patillo (2000) señalan que éste es uno de los más importantes precios relativos y que los economistas ignoran muchas de sus propiedades empíricas. En su examen de 42 países del Africa subsahariano para el período 1990-1996, encuentran que en la mitad de ellos la persistencia de las perturbaciones es corta -inferior a cuatro años-, mientras que en un tercio de ellos las perturbaciones son permanentes. En cuanto a las implicaciones de política, señalan que si los shocks son de corta vida hay un margen para lograr cambios en el ahorro nacional $\mathrm{y}$ en el financiamiento internacional y suavizar así el sendero del consumo nacional. Pero si los shocks son de larga duración, las políticas anticíclicas sirven poco para lograr un nuevo equilibrio.

El efecto de las perturbaciones en el crecimiento económico ha sido tratado en Dehn (2000b): la dependencia de exportaciones primarias confiere a las perturbaciones adversas, además de un efecto ex post, un efecto ex ante de incertidumbre, los que reducen las perspectivas de crecimiento; las perturbaciones positivas, en cambio, se diluyen rápidamente y no tienen efectos de importancia en el largo plazo.

En resumen, la reciente literatura empírica y teórica no ha asignado a los shocks en los precios de los productos básicos la misma importancia que ha dado a las crisis financieras. Actualmente se ha encontrado evidencia empírica de la persistencia de esas perturbaciones y de que la fase de declinación de los precios dura más que su fase de auge. Es decir, existen elementos que abonan la existencia de una tendencia secular a la caída de los precios. Pero hay también indicios empíricos de que no es cierta la percepción de que los precios de los productos básicos se mueven juntos, lo que significa que no habría caídas generalizadas de sus precios.

\section{III}

\section{Evolución y composición de las exportaciones bolivianas}

En esta parte del trabajo se analiza brevemente la evolución de las exportaciones bolivianas y su composición, y se presenta el índice de precios de su canasta exportadora de productos básicos y el índice mensual de la relación de intercambio entre productos primarios y manufactureros.

En un período más amplio, dicha relación nos muestra que desde 1980 la economía boliviana ha experimentado un deterioro constante y persistente. En la década de 1980 sufrió dos caídas de precios; la primera significó una baja de $8.3 \%$ y $11.2 \%$ en 1981 y 1982, respectivamente, y la segunda una en torno al $12 \%$ anual entre 1985 y 1987; ambas estuvieron relacionadas con la caída de los precios de los minerales, en especial del estaño. Después, en la década de 1990, soportó dos fuertes shocks de términos de intercambio. El primero, que duró cuatro años, se inició en 1992, cuando dicha relación registró un deterioro de $16 \%$ debido, en parte, a la caída de los precios del gas tras cambios en el contrato de exportación de ese producto a la Argentina. El segundo, que duró menos, se registró en 1998, estuvo vinculado con 
GRAFICO 1

Bolivia: Relación anual de precios del intercambio ${ }^{a}$ $(1980=100)$

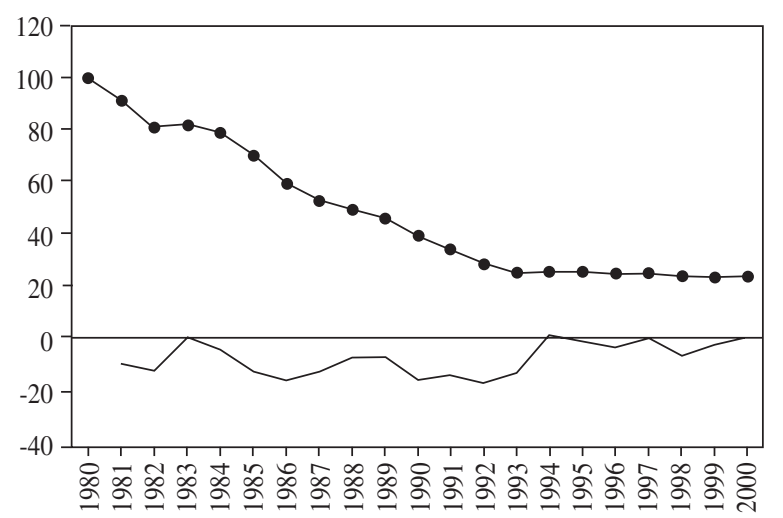

$\longrightarrow$ IRPI $80=100 \div$ Var RPI

Fuente: Elaboración propia con datos del Instituto Nacional de Estadísticas (INE).

a IRPI: índice de la relación de precios del intercambio. Var. RPI: variación porcentual del IRPI.

la crisis asiática y la crisis financiera internacional y el deterioro fue de $5 \%$.

Los términos de intercambio (gráfico 1) tuvieron un comportamiento ondulatorio, con fases de deterioro prolongadas y muy pocos años de recuperación entre 1980 y 2000.

\section{Las exportaciones bolivianas durante el dece- nio de 1990}

Entre 1990 y 1999 los ingresos nominales de exportación bolivianos fueron en promedio de 1018.7 millones de dólares anuales (15\% del PIB). El comportamiento de los ingresos fue relativamente volátil, con una desviación estándar de 176.8 millones de dólares, equivalente al $17 \%$ de la media.

El valor nominal de las exportaciones en la década creció a una tasa anual de $1.1 \%$, muy baja si se la compara, por ejemplo, con las de crecimiento de las exportaciones mundiales (5.5\%), de Sudamérica (4.9\%) y de Chile (7.2\%). En valores reales, las exportaciones disminuyeron $5.7 \%$ en 10 años y su deterioro se registró en dos oportunidades: entre 1990 y 1992, con una caída del $27 \%$ como consecuencia de las menores exportaciones de gas a la Argentina, y en 1998 y 1999, debido a la crisis internacional, con una caída acumulada del $16 \%$. La economía boliviana, por lo tanto, experimentó en el decenio de 1990 dos shocks externos, que se tradujeron en significativas caídas de sus ingresos reales de exportación (cuadro 1).

El bajo desempeño de las exportaciones bolivianas va a contramano del elevado dinamismo del comercio mundial. Mientras que en diez años crecieron sólo $10 \%$ en términos nominales, las exportaciones mundiales aumentaron en $60 \%$.

La composición de las exportaciones bolivianas en el decenio siguió concentrada en los productos básicos, cuya participación en el total exportado declinó levemente de $86.6 \%$ en 1990 a $84 \%$ en 1999 . La de las exportaciones de manufacturas, en cambio, sólo aumentó menos de un punto porcentual en diez años, de $13.2 \%$ a $14 \%$.

La estructura de las exportaciones bolivianas es muy asimétrica con respecto a aquélla de las exportaciones mundiales. Según la omc (2000), las manufacturas constituyen más de las tres cuartas partes de las exportaciones mundiales, pero menos de un sexto de las exportaciones bolivianas. Esta participación es menor que la que exhiben los países africanos (30\%) y muy inferior al promedio de América Latina (60\%). Por lo tanto, el lento incremento de las exportaciones bolivianas está asociado a las bajas tasas de crecimiento de sus exportaciones de productos básicos. En cambio, las exportaciones de manufacturas, que aumentaron

CUADRO 1

\section{Exportaciones de Bolivia en valores nominales y reales ${ }^{\mathrm{a}}$ (Millones de dólares)}

\begin{tabular}{lrcr}
\hline Años & $\begin{array}{c}\text { Valor } \\
\text { nominal }\end{array}$ & $\begin{array}{c}\text { Indice de precios } \\
\text { de importación }\end{array}$ & $\begin{array}{r}\text { Valor } \\
\text { real }\end{array}$ \\
\hline 1990 & 937.5 & 100.0 & 937.5 \\
91 & 873.8 & 105.5 & 828.2 \\
92 & 742.1 & 108.5 & 684.0 \\
93 & 786.7 & 110.7 & 710.7 \\
94 & 1091.0 & 114.1 & 956.2 \\
95 & 1139.1 & 118.2 & 963.7 \\
96 & 1216.2 & 121.1 & 1004.3 \\
97 & 1255.6 & 120.0 & 1046.3 \\
98 & 1110.1 & 118.4 & 937.6 \\
99 & 1034.8 & 117.1 & 883.7 \\
TCG & 1.1 & 1.8 & -0.7 \\
Var \% 99/90 & 10.4 & 17.1 & -5.7 \\
Media & 1018.7 & 113.4 & 895.2 \\
DE & 176.8 & 7.0 & 120.2 \\
CV & 0.17 & 0.06 & 0.13 \\
\hline
\end{tabular}

Fuente: Elaboración propia con datos del Instituto Nacional de Estadísticas (INE).

a TCG: Tasa de crecimiento geométrica. DE: Desviación estándar. CV: Coeficiente de variación. 
más de 3.5\% anual en el decenio, tienen poca incidencia en el total.

Las distintas exportaciones primarias exhibieron comportamientos muy diferenciados en el decenio; las exportaciones agrícolas de Bolivia crecieron a una tasa anual de $10.3 \%$, muy superior a la mundial de $3.1 \%$, mientras que sus exportaciones de hidrocarburos disminuyeron anualmente en $11 \%$ debido, como ya se ha dicho, al fin del contrato de exportación de gas a la Argentina. Las exportaciones mineras del país se estancaron durante diez años, mientras que las del mundo crecían $1.5 \%$ por año.

El poco dinamismo de las exportaciones bolivianas se debió a la caída de los precios unitarios de exportación, puesto que mientras el índice de valor subió $10 \%$, el de volumen aumentó $57 \%$, lo que implica una contracción de 30\% del índice de valor unitario de las exportaciones. Esta baja fue mayor que la disminución de los precios unitarios mundiales de la minería $(22 \%)$ y la agricultura ( $8 \%$ ), y mayor también que la del índice de precios de los productos básicos (13\%). La situación se explica, en parte, por la reducción drástica, en dos tercios, del precio del gas en el contrato con Argentina, entre el primer trimestre de 1991 y el segundo de 1992.

Junto con declinar los precios de exportación bolivianos, subieron $17.1 \%$ los precios unitarios de importación, lo que se tradujo en un fuerte deterioro (40\%) de los términos de intercambio. Si se excluye el efecto inicial de la caída del precio del gas en los primeros años de la década de 1990, el empeoramiento es de $22 \%$. El efecto de la relación del intercambio en los ingresos de exportación, estimado por el INE, indica que si los precios de exportación hubieran seguido el comportamiento de los precios de importación en 1999, el país hubiera tenido un ingreso adicional de 597 millones de dólares. Por el deterioro de la relación de precios del intercambio, Bolivia está transfiriendo al exterior parte de su esfuerzo productivo interno y sufre una disminución de su ingreso real. El caso boliviano en la década de 1990 es una prueba empírica de ese deterioro.

En resumen, el bajo desempeño de las exportaciones bolivianas no está en línea con el dinamismo de las exportaciones mundiales, fuertemente concentradas en manufacturas, debido a su alta dependencia de productos básicos cuyos precios experimentaron dos fuertes shocks externos en la década de 1990, con efectos negativos para los ingresos reales de exportación.

\section{El índice de precios de la canasta de produc- tos básicos de exportación bolivianos}

La estructura de las exportaciones bolivianas depende altamente de los productos básicos, que representan el $84 \%$ de las exportaciones totales del país. La gama de tales productos es amplia y, a diferencia de la mayoría de los países en desarrollo, no presenta la clásica predominancia de unos pocos de ellos. Está diversificada por sectores económicos, puesto que ha dejado de depender de un sector en particular.

Para medir los niveles y las variaciones de los precios de los productos básicos de la canasta de exportación, el Banco Central de Bolivia cuenta con una serie de índices de precios. La canasta está compuesta por 13 productos básicos, o por 11 si se excluyen los hidrocarburos (cuadro 2).

Esa canasta tiene las siguientes características:

- Para cada producto del cual se dispone de información diaria, se multiplica su cotización por su ponderación en la canasta según su participación en el valor de las exportaciones en 1996. Se utiliza, por lo tanto, el índice Laspeyres, es decir:

$$
\mathrm{IPL}=\frac{\sum \mathrm{Pn} \mathrm{Qo}}{\sum \mathrm{Po} \mathrm{Qo}}
$$

CUADRO 2

\section{Bolivia: Canasta de productos básicos de exportación, $1996^{a}$}

(Participación porcentual en el total exportado)

\begin{tabular}{llr}
\hline Productos & Cotización & 1996 \\
\hline Zinc & CUS/LBF & 13.5 \\
Oro & US/OTF & 10.5 \\
Estaño & US/LBF & 7.5 \\
Plata & US/OTF & 5.6 \\
Soja & US/TM & 5.3 \\
Harina de soja & US/TM & 9.0 \\
Aceite de soja & US/TM & 3.6 \\
Maderas & US/TM & 6.9 \\
Algodón & Us/TM & 2.9 \\
Café & CUS/LB & 1.4 \\
Azúcar & US/TM & 2.6 \\
Gas & US/MPC & 8.3 \\
Petróleo & US/BARRIL & 3.4 \\
& & \\
Total prod. básicos & & 80.5 \\
Total sin combustibles & & 68.8 \\
Total exportado & &
\end{tabular}

Fuente: Elaboración propia con base en datos del Banco Central de Bolivia.

a US: dólares. cus: centavos de dólar. LB: libra. LBF: libra fina. TM: toneladas métricas. MPC: millar de pies cúbicos. OTF: onza troy fina. 
- Los productos básicos representan el $80.5 \%$ del valor exportado en 1996 y si se excluyen los hidrocarburos el peso disminuye a $68.8 \%$. El índice se calcula a su vez, como también lo hace el FMI, con y sin combustibles, para diferenciar el efecto de las fuertes fluctuaciones de los precios del petróleo.

- La disponibilidad de información es en tiempo real a través del servicio de Reuter, salvo sobre las maderas, para las cuales la fuente de información es el Viceministerio de Exportaciones, y sobre el gas natural, para el cual proporciona información Yacimientos Petrolíferos Fiscales Bolivianos (YPFB), cuyos precios tienen un rezago de un mes.

- El año base es el precio observado en el mes de diciembre de 1996, que es consistente con el año base para el cálculo del tipo de cambio real efectivo.

Los 13 productos que forman la canasta se agruparon en tres sectores con el fin de diferenciar com- portamientos sectoriales: el sector minero, que comprende cuatro productos; el sector agropecuario, que incluye siete productos; y el sector hidrocarburos, que abarca el gas y el petróleo. Sin embargo, como el gas y el petróleo tienen comportamientos diferentes debido al contrato de exportación de gas a la Argentina, por consideraciones prácticas aparecen en forma separada. En el caso de los productos agropecuarios se creó un subgrupo, el complejo de la soja, que incluye la soja en grano, la harina de soja y el aceite de soja. Cada producto mantuvo su ponderación, por lo que la ponderación del sector en el total corresponde a la suma de cada uno de sus productos.

En síntesis, se dispone de los siguientes indicadores:

- Indices de precios por cada producto: 13 en total.

- Indice de precios general (IPB).

- Indice de precios general sin combustibles (IPB s/c).

- Indice de precios mineros (IPM).

- Indice de precios agropecuarios (IPA).

- Indice de precios del complejo de la soja.

\section{IV}

\section{Tendencia, shocks y comovimientos de los precios de los productos básicos}

En esta parte del trabajo, con base en indicadores empíricos, se analiza la tendencia y los shocks de corto plazo de los precios de los productos básicos, así como su reciente declinación, con el fin de determinar si se está frente a un comportamiento temporal, por lo cual la perturbación tendería a disiparse, o si se trata de un componente permanente o estructural. También se busca determinar si los precios de los productos de la canasta de exportación se mueven juntos, es decir, si se encuentran en el mismo período de auge o declinación, o si tienen un comportamiento anticíclico que compense la fase de declinación de un producto con el auge de otro.

\section{Tendencia de los precios de los productos básicos}

Para analizar el comportamiento de los precios de los productos básicos en la década de 1990, utilizando los índices de precios con y sin combustibles, se han descompuesto las series cronológicas de precios en dos componentes: la tendencia de largo plazo y el shock de corto plazo.

A partir de enero de 1992, los precios de los productos básicos presentan fases cortas (alrededor de ocho meses) de contracción y recuperación, pero a partir de abril de 1994 inician una fase de auge de 25 meses, la más larga de la década hasta abril de 1996, en la cual el índice alcanza su nivel más alto, de 107.4 (gráfico 2). Posteriormente retorna el ciclo corto (seis meses) de contracción y recuperación, hasta que en junio de 1997, con la crisis asiática, comienza el ciclo de contracción más largo de los años noventa (25 meses) que termina en julio de 1999 con el índice de precios en su nivel más bajo (81.5). Sólo en agosto de 1999 los precios empiezan a recuperarse en forma sostenida hasta mayo de 2000 y con fluctuaciones hasta septiembre del mismo año. El inicio de la fase de recuperación de los precios fue más rápido en el caso del petróleo; partió en marzo de 1999 con la decisión de la Organización de Países Exportadores de Petróleo (OPEP) de reducir su producción. 


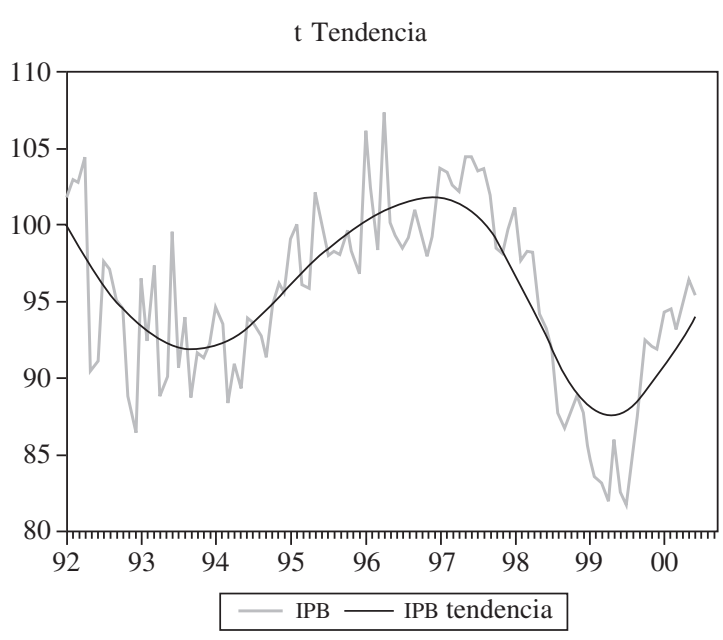

Fuente: Elaboración propia con datos del Banco Central de Bolivia.

La duración de la fase de auge más prolongada (25 meses) fue la misma que la duración de la fase más larga de declinación. La magnitud de la caída de los precios en la fase de descenso, $13.8 \%$ en el índice total y $15.2 \%$ en el índice sin combustibles, fue mayor que la magnitud del alza en la fase de bonanza, 10.8\% en el índice total y $11.7 \%$ en el índice sin combustibles. El nivel que señala el índice total para el inicio de la etapa de recuperación en 1999 fue de 81.6, menor que aquél a partir del cual se inició la recuperación en 1993, que fue de 88.6.

La tendencia de largo plazo, obtenida a través del uso del método de suavización mediante el filtro de Hodrick-Prescott (1997), tiene un comportamiento ondulatorio que es una característica clave de las cotizaciones de los productos básicos ${ }^{3}$ (gráfico 2).

El filtro de Hodrick-Prescott es un filtro lineal de dos lados, que computa la serie suavizada $s$ de $y$, minimizando la varianza de $y$ alrededor de $s$, sujeta a un parámetro de penalización que restringe la segunda diferencia de $s$. Esto significa que el filtro de HodrickPrescott selecciona $s_{t}$ para minimizar la siguiente función objetivo:

$$
\sum_{t=1}^{T}\left(y_{t}-s_{t}\right)^{2}+\lambda \sum_{t=2}^{T-1}\left\{\left(s_{t+1}-s_{t}\right)-\left(s_{t}-s_{t-1}\right)\right\}^{2}
$$

El parámetro de penalización $\lambda$ controla la suavización de la serie $\mathrm{s}_{\mathrm{t}}$. Mientras mayor sea $\lambda$ más suavi-

\footnotetext{
${ }^{3}$ Véase Cashin, McDermott y Scott (1999a).
}

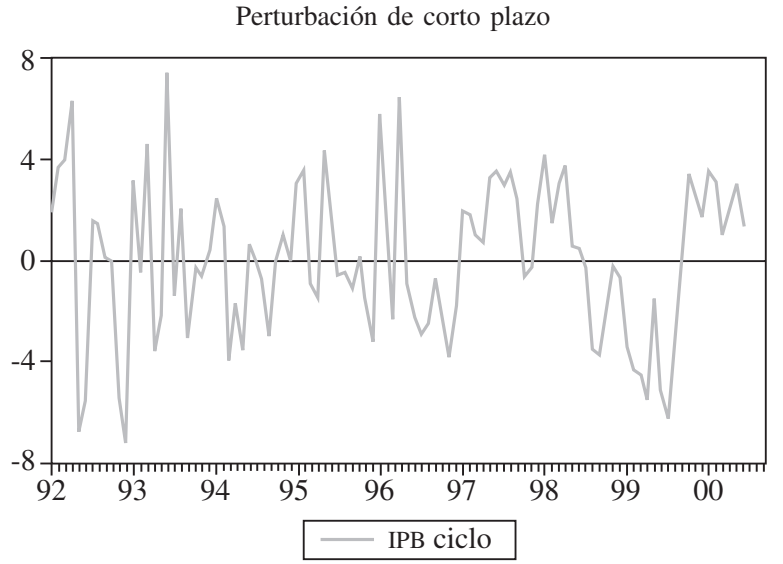

zada es la serie. Si $\lambda \rightarrow \infty, s_{t}$ se aproxima a una tendencia lineal. En este trabajo $\lambda=14.400$, de acuerdo con la sugerencia de Hodrick-Prescott para series mensuales.

Suavizando la tendencia en la década de 1990, nos encontramos con un comportamiento ondulatorio que empieza con una fase de contracción de 18 meses, hasta agosto de 1993; le sigue una fase larga de recuperación de 36 meses hasta agosto de 1996, posteriormente una fase de contracción de 49 meses y el inicio de una fase de recuperación a mediados de 1999 y durante los tres primeros trimestres de 2000.

La serie que muestra los shocks de corto plazo de los precios se obtiene residualmente como la diferencia entre la serie de tendencia de largo plazo y la serie original observada. Muestra que cuando un mercado está a la baja, los precios observados están por debajo de la tendencia y cuando es un mercado alcista, los precios están por encima de la tendencia. Entre 1992 y 1996 presentan un comportamiento muy fluctuante, pero a partir de diciembre de 1996 hasta abril de 1998 hay un comportamiento sostenido de recuperación de 17 meses, en que los precios observados son superiores a la tendencia. Sin embargo, entre mayo de 1998 y septiembre de 1999 los precios observados son muy inferiores a la tendencia, lo que quiere decir que en este período se sintió más el efecto adverso de la perturbación de precios, aunque la declinación se había iniciado antes, en junio de 1997. Así, los precios llegaron a niveles de nueve puntos por debajo de la tendencia del índice, como sucedió en abril y julio de 1999. 


\section{2. ¿Shock persistente o temporal?}

Para determinar cuán importante es el papel que desempeñan los shocks persistentes se procedió en dos etapas. En la primera se establecieron las propiedades de las series cronológicas, utilizando las pruebas de raíz unitaria mediante el test Dickey-Fuller y el test DickeyFuller Ampliado. El cuadro 3 presenta los valores críticos para los tests en niveles y en primeras diferencias. Si y es estacionaria, los shocks son transitorios; en cambio, si $y$ es un proceso integrado de orden uno, tiene un componente permanente.

En la segunda etapa se procedió a determinar el tamaño del componente permanente mediante la metodología de Cochrane, que mide la persistencia de los shocks mediante el examen de la varianza de sus diferencias, la que tiene la siguiente forma:

$$
\mathrm{EP}=\left(\frac{1}{k}\right) * \frac{\operatorname{var}\left(y_{t}-y_{t-k}\right)}{\operatorname{var}\left(y_{t}-y_{t-1}\right)}
$$

Con base en el estadístico de persistencia (EP), si la razón es igual a 1 , la variable $y$ sigue un proceso de paseo aleatorio, y todas las perturbaciones son permanentes. Si $y$ es estacionario todas las perturbaciones se disipan, por lo que la razón tiende a cero, lo que indica que las perturbaciones serán temporales. Si y es un proceso integrado de orden uno, tiene componentes transitorios y permanentes, por lo tanto la razón convergerá a la razón entre la varianza del shock permanente y la varianza total de la variable $y$. De este modo, mientras más cercana es la razón a la unidad, mayor es el tamaño del componente permanente y menor es la importancia relativa de las perturbaciones temporales. Se aplicó esta medición para $\mathrm{k}=1,12$ y 24 rezagos por tratarse de datos mensuales (cuadro 4).
CUADRO 4

Bolivia: Persistencia de los shocks en los índices de precios de exportación

(Razón de las varianzas)

\begin{tabular}{lccc}
\hline & \multicolumn{3}{c}{ Rezagos (t) } \\
\cline { 2 - 4 } & 1 & 12 & 24 \\
\hline Productos básicos & 1 & 0.34 & 0.26 \\
Productos básicos sin combustibles & 1 & 0.38 & 0.38 \\
Agrícolas & 1 & 0.28 & 0.24 \\
Metales & 1 & 0.69 & 0.35 \\
Complejo de la soja & 1 & 0.41 & 0.40 \\
Combustibles & 1 & 0.26 & 0.21 \\
\hline
\end{tabular}

Fuente: Elaboración propia con datos del Banco Central de Bolivia.

En el caso boliviano, las series de precios con y sin combustibles y por sectores (metales, agrícola, complejo de la soja y combustibles) son integradas que siguen un proceso de orden uno. Se encontró que en cada serie de precios (total y por sectores) los shocks permanentes desempeñan un papel en la explicación de la varianza de los precios mensuales.

El efecto del componente permanente de los shocks es mayor en los precios de los metales (origina $69 \%$ de su varianza mensual), mientras que en los sectores agrícola y de combustibles la cifra es de $25 \%$ y en los índices generales, con y sin combustibles, en torno al $33 \%$. En las series de precios de los metales dicho componente exhibe un bajo grado de persistencia, puesto que a 24 meses disminuye de $69 \%$ a $35 \%$. En los demás sectores y en el índice general el componente permanente se mantiene. La presencia de shocks transitorios da pie para aplicar políticas de estabilización de precios, como las medidas que para tal efecto recomienda el Fondo Monetario Internacional (FMI).

No obstante, la presencia de shocks permanentes indica que la debilidad de los precios de los productos básicos observada a partir de 1997 no es solamente un

CUADRO 3

Análisis de raíz unitaria: ${ }^{\mathrm{a}}$ Test Dickey-Fuller y test Dickey-Fuller Ampliado

\begin{tabular}{|c|c|c|c|c|c|c|c|c|c|c|c|}
\hline \multirow[t]{2}{*}{ Serie } & \multicolumn{3}{|c|}{ Niveles } & \multicolumn{2}{|c|}{ Valores críticos } & \multicolumn{3}{|c|}{ Primeras diferencias } & \multirow{2}{*}{$\begin{array}{c}\text { Orden de } \\
\text { integración }\end{array}$} & \multicolumn{2}{|c|}{ Valores críticos } \\
\hline & $\overline{\mathrm{N}^{\circ} \text { rezagos }}$ & Modelo & t-Estadístico & $1 \%$ & $5 \%$ & $\overline{\mathrm{N}^{\circ} \text { rezagos }}$ & Modelo & t-Estadístico & & $1 \%$ & $5 \%$ \\
\hline IPB & 4 & $\mathrm{C}$ & -1.416578 & -4.055 & -3.4561 & 4 & B & -5.217714 & 1(1) & -3.4993 & -2.8915 \\
\hline IPBSC & 4 & $\mathrm{C}$ & -1.343285 & -4.0521 & -3.4548 & 4 & A & -4.471892 & 1(1) & -2.5866 & -1.9433 \\
\hline Agrícola & 4 & $\mathrm{C}$ & -1.511792 & -4.0521 & -3.4548 & 5 & A & -4.587867 & 1(1) & -2.5868 & -1.9434 \\
\hline Compsoya & 4 & $\mathrm{C}$ & -1.5352 & -4.0521 & -3.4548 & 0 & A & -13.7045 & 1(1) & -2.5858 & -1.9432 \\
\hline Metales & 2 & $\mathrm{C}$ & -3.0101 & -4.0503 & -3.4539 & 2 & $\mathrm{C}$ & -5.35682 & 1(1) & -3.4972 & -2.8906 \\
\hline Combustibles & 6 & $\mathrm{C}$ & -1.616115 & -4.054 & -3.4557 & 8 & A & -3.1834 & 1(1) & -2.5883 & -1.9436 \\
\hline
\end{tabular}

Fuente: Elaboración propia con datos del Banco Central de Bolivia.

a A: No incluye componentes determinísticos. B: Incluye constante pero no tendencia. C: Incluye constante y tendencia.

b Al ser superior el $t$ estadístico en primeras diferencias a los valores críticos indica que las series son integradas de orden uno. 
fenómeno transitorio, resultado de un ciclo anormal asociado a la crisis asiática (aunque con esta crisis se haya iniciado la fase de declinación). Por ello la caída no se revirtió automáticamente y tampoco se han recuperado los precios después que las economías asiáticas lograron su recuperación económica en 1999. Tampoco la caída de los precios está asociada a la fluctuación cíclica de la economía mundial, puesto que se ha dado en plena etapa de alto crecimiento de la economía estadounidense y de crecimiento de la economía mundial. La recuperación de los precios, excepto el del petróleo, ha sido más lenta que lo esperado y aún no los ha llevado a los niveles anteriores al inicio de la fase de auge.

En síntesis, en el caso boliviano existe un componente permanente en los shocks de los precios de los productos básicos, aunque menor que el encontrado para países en desarrollo. ${ }^{4}$ A nivel sectorial, este componente es mayor en los metales, aunque de baja persistencia. Por este motivo, la reciente perturbación de precios no ha tendido a disiparse con rapidez.

\section{La concordancia o comovimientos en las fases de los ciclos}

El comportamiento cíclico de los precios lleva a preguntarse si las series de precios por sectores y por producto se mueven juntas en las fases expansivas y contractivas del ciclo. La concordancia es una medida de comovimientos que permite comparar los patrones cíclicos de las series de precios. La prueba estadística permite establecer cuál es la proporción de tiempo en que los precios de dos productos transcurren o permanecen en la misma fase del ciclo. ${ }^{5}$

Para tal efecto se especifica una variable dicótoma para cada variable original o serie de precios que toma el valor de uno cuando la variable se encuentra en la fase expansiva y de cero cuando se encuentra en la fase contractiva. El grado de concordancia entre los ciclos de dos series de precios es entonces:

$$
C_{i j}=T^{-1}\left\{\sum_{t=1}^{T}\left(S_{i, t} S_{j, t}\right)+\left(1-S_{i, t}\right)\left(1-S_{j, t}\right)\right\}
$$

donde $C_{\mathrm{ij}}$ es el estadístico de concordancia que mide la razón en que dos series de precios se encuentran en el mismo estado, $T$ es el número de observaciones, $S_{\mathrm{i}, \mathrm{t}}$

\footnotetext{
4 Véase Cashin, Liang y McDermott (1999).

5 Véase una explicación más detallada sobre la concordancia en Cashin, McDermott y Scott (1999b).
}

es la variable dicótoma asociada a la variable original $x_{\mathrm{i}}$ en el momento $t$, y $S_{\mathrm{j}, \mathrm{t}}$ es la variable dicótoma asociada a la variable original $x_{\mathrm{j}}$ en el momento $t$.

Cuando el estadístico de concordancia adopta valores cercanos a uno, las series de precios comparadas son procíclicas; cuando el estadístico es cercano a cero las series de precios son contracíclicas, y finalmente, cuando la concordancia toma valores cercanos a 0.5 , la probabilidad de que las series sean procíclicas es igual a la de que sean contracíclicas. Para fines prácticos, en este trabajo se toma un rango de $+/-0.10$ arbitrario $^{6}$ solamente para diferenciar de los casos cercanos a 0.5 , de manera que un coeficiente mayor a 0.6 indicaría que las series tenderían a ser procíclicas y un coeficiente menor a 0.4 , que tenderían a ser anticíclicas.

Los resultados para el período enero de 1992 a septiembre de 2000 muestran (cuadro 5) que la serie del índice de precios que excluye los combustibles presenta un alto grado de concordancia $(0.71)$ con la serie de precios de los combustibles, es decir, son variables procíclicas. Por lo tanto, el hecho de que un país sea exportador de combustibles no lo aísla del ciclo de los otros productos primarios. Asimismo, si se excluye los combustibles, el resto de los productos de exportación presenta comportamientos procíclicos. Esto se observa en forma más clara a nivel de sectores, donde los precios de los productos agrícolas son más procíclicos con los de los combustibles (0.81) que los precios de los metales (0.60).

En la década de 1990 Bolivia desarrolló las exportaciones agrícolas y en especial las del complejo de la soja. Se suponía que dicha diversificación le permitiría disminuir su dependencia del sector minero. Pero los indicadores sectoriales de concordancia muestran que no se podría decir si los precios de los metales son procíclicos o no con relación a los precios de los productos agrícolas (0.45) o del complejo de la soja (0.48), puesto que los indicadores de concordancia son muy cercanos a 0.50 .

Sin embargo, aquí se realiza el análisis por producto para identificar la existencia de comovimientos entre precios de productos del sector minero y del sector agrícola (cuadro 6). De un total de 28 posibles combinaciones entre pares de productos agrícolas y mineros que forman parte de la canasta de exportación, se tiene que existen nueve pares de productos (un 32\%), cuyas series de precios se mueven juntas en las fases del ciclo, es decir, se trata de productos procíclicos. Los

\footnotetext{
${ }^{6}$ Cabe hacer notar que se requiere de un análisis más detallado para justificar cuál sería el rango adecuado para diferenciar de los casos cercanos a 0.50 .
} 


\begin{tabular}{|c|c|c|c|c|c|c|}
\hline & Metales & $\begin{array}{c}\text { Complejo de } \\
\text { la soja }\end{array}$ & $\begin{array}{c}\text { Sector } \\
\text { agrícola }\end{array}$ & Combustibles & $\begin{array}{l}\text { Indice de precios } \\
\text { general (IPB) }\end{array}$ & $\begin{array}{c}\text { IPB } \\
\text { sin combustibles }\end{array}$ \\
\hline Metales & 1.000 & & & & & \\
\hline Complejo de la soja & 0.476 & 1.000 & & & & \\
\hline Sector agrícola & 0.448 & 0.724 & 1.000 & & & \\
\hline Combustibles & 0.600 & 0.533 & 0.810 & 1.000 & & \\
\hline IPB & 0.505 & 0.705 & 0.943 & 0.752 & 1.000 & \\
\hline IPB sin combustibles & 0.771 & 0.381 & 0.657 & 0.714 & 0.676 & 1.000 \\
\hline
\end{tabular}

Fuente: Elaboración propia con datos del Banco Central de Bolivia.

CUADRO 6

Bolivia: Concordancia entre los precios de los productos agrícolas y de los metales

\begin{tabular}{llc}
\hline Minería & \multicolumn{1}{c}{ Agricultura } & Concordancia \\
\hline & Productos procíclicos & \\
Oro & Soja & 0.62 \\
Oro & Algodón & 0.73 \\
Oro & Café & 0.61 \\
Oro & Azúcar & 0.68 \\
Oro & Aceite & 0.70 \\
Zinc & Algodón & 0.61 \\
Estaño & Aceite & 0.70 \\
Plata & Aceite & 0.73 \\
Plata & Madera & 0.62 \\
& & \\
Zinc & Productos anticíclicos & \\
Oro & Madera & 0.32 \\
Estaño & Madera & 0.39 \\
Estaño & Soja & 0.33 \\
Plata & Harina & 0.37 \\
Plata & Soja & 0.22 \\
& Harina & 0.18 \\
\hline
\end{tabular}

Fuente: Elaboración propia con datos del Banco Central de Bolivia.

más procíclicos son el oro, la plata, el algodón y el aceite. Los productos anticíclicos representan menos pares de combinaciones (seis), resaltando la relación del precio del estaño con el de la soja $(0.33)$ y de la plata con el de la soja (0.22).
Respecto a los combustibles, se tiene que serían procíclicos a los precios del gas los precios de los productos mineros, excepto la plata, y los precios de los productos agrícolas, salvo el aceite de soja. Este indicador es significativo, puesto que para el decenio de 2000 se ha centrado la esperanza en las exportaciones de gas, que tiene muy pocos productos anticíclicos. A los precios del petróleo serían procíclicos los precios de los productos mineros, con excepción de la plata, y de los productos agrícolas, salvo las maderas y el azúcar.

En síntesis, en el caso boliviano, a diferencia de lo observado para los países en desarrollo por Cashin, McDermott y Scott (1999b), hay un alto grado de concordancia a nivel sectorial, lo que indicaría que la diversificación de las exportaciones de productos básicos no ha permitido atenuar los efectos del ciclo de los precios, es decir, no ha sido una diversificación anticíclica. Sin embargo, a nivel de productos se ha encontrado que un tercio de las exportaciones corresponde a productos contracíclicos. Los precios de la plata y el estaño (que representaron $13.1 \%$ de las exportaciones en 1996) serían contracíclicos respecto a los de la soja y la harina (que representaron $14.3 \%$ de dichas exportaciones) y los precios de la plata respecto a los del gas (que representaron un $8 \%$ ).

\section{$\mathrm{V}$ \\ Volatilidad y riesgo de la cartera de exportaciones}

En esta parte del artículo se complementa el examen del comportamiento de los precios de los productos básicos de exportación con el análisis de la volatilidad de los precios a través del coeficiente de variación, que relaciona la desviación estándar con la media, ${ }^{7}$ y con

\footnotetext{
7 En términos de tanto por uno. Generalmente el coeficiente de variación viene expresado en porcentajes (Moya, 1991).
} 
el cálculo de riesgo de la cartera de los productos que conforman la canasta exportadora.

\section{Volatilidad de los precios de exportación}

Una característica importante y ampliamente aceptada en el comportamiento de los precios de los productos básicos es su elevada volatilidad. En el caso boliviano, tanto el índice de precios general como el que excluye los combustibles presentan una volatilidad de 0.06 (cuadro 7). En el índice general la volatilidad es menor que el 0.135 calculado por Cashin, Liang y McDermott (1999) para una canasta de 56 productos en el período 1957-1998, mientras que es un poco mayor al 0.04 calculado para la canasta que excluye los combustibles.

A nivel de sectores, los precios de los metales (0.05) son los menos volátiles y los precios de los combustibles (0.22) los más volátiles, mientras que los precios de los productos agrícolas tendrían una volatilidad intermedia (0.11). En el ámbito de productos específicos, los precios de la harina $(0.21)$ y el aceite de soja (0.25) presentan una alta volatilidad, similar a la de los combustibles, mientras que los precios del café, el azúcar y el algodón estarían entre los más volátiles de la canasta boliviana de exportación.

La evolución de la volatilidad se calcula aquí a lo largo del período enero 1992 a septiembre de 2000, medida a partir de los valores acumulados de los coeficientes de variación medios anuales (gráfico 3). En el caso del índice de precios general que incluye los combustibles, se observa que se ha mantenido relativamente constante, con un incremento de la volatilidad a partir de 1997, mientras que el índice de precios que excluye los combustibles presenta una volatilidad creciente. A nivel de sectores, los precios de los metales muestran una volatilidad relativamente constante a lo largo del período, mientras que tanto los precios agrícolas como los del petróleo exhiben una volatilidad creciente. La crisis internacional significó un aumento de la volatilidad en todos los sectores de exportación; sin embargo, ese aumento no fue simultáneo ni constante. En los metales la volatilidad se incrementó en 1997, pero después disminuyó; en los productos

CUADRO 7

Bolivia: Estadísticos descriptivos de los índices de precios de los productos básicos, enero de 1990 a septiembre de 2000

\begin{tabular}{|c|c|c|c|c|c|}
\hline & Media & $\begin{array}{c}\text { Desviación } \\
\text { estándar }\end{array}$ & $\begin{array}{l}\text { Coeficiente } \\
\text { de variación }\end{array}$ & $\begin{array}{l}\text { Coeficiente } \\
\text { de asimetría }\end{array}$ & $\begin{array}{l}\text { Coeficiente } \\
\text { de curtosis }\end{array}$ \\
\hline Zinc & 105.52 & 12.52 & 0.12 & 0.68 & 3.56 \\
\hline Oro & 88.97 & 9.61 & 0.11 & -0.22 & 1.69 \\
\hline Estaño & 94.09 & 7.59 & 0.08 & -0.11 & 3.66 \\
\hline Plata & 97.72 & 14.57 & 0.15 & -0.07 & 3.18 \\
\hline Indice de metales & 97.33 & 5.05 & 0.05 & 0.02 & 3.02 \\
\hline Soja & 93.65 & 14.23 & 0.15 & 1.36 & 5.52 \\
\hline Harina de soja & 83.10 & 17.27 & 0.21 & 0.66 & 2.82 \\
\hline Aceite de soja & 104.93 & 27.41 & 0.26 & 2.62 & 18.57 \\
\hline Complejo de la soja & 90.73 & 14.29 & 0.16 & 0.29 & 3.06 \\
\hline Madera & 94.13 & 18.36 & 0.20 & -0.08 & 3.12 \\
\hline Algodón & 91.27 & 29.79 & 0.33 & 2.12 & 11.77 \\
\hline Café & 90.66 & 36.05 & 0.40 & 0.71 & 4.63 \\
\hline Azúcar & 100.10 & 33.29 & 0.33 & 2.15 & 14.98 \\
\hline Indice agrícola & 92.14 & 10.49 & 0.11 & 0.26 & 2.42 \\
\hline Gas & 97.10 & 25.15 & 0.26 & 2.57 & 12.25 \\
\hline Petróleo & 77.11 & 18.26 & 0.24 & 1.02 & 4.92 \\
\hline Indice de precios de combustibles & 86.16 & 19.32 & 0.22 & 1.72 & 7.79 \\
\hline Indice de precios sin combustibles & 94.76 & 6.08 & 0.06 & 0.25 & 2.39 \\
\hline Indice general de precios (IPB) & 95.18 & 5.95 & 0.06 & -0.30 & 2.45 \\
\hline
\end{tabular}

Fuente: Elaboración propia con datos del Banco Central de Bolivia. 
Bolivia: Volatilidad de los precios de los productos básicos de exportación (Coeficiente de variabilidad acumulativo anual)

Metales

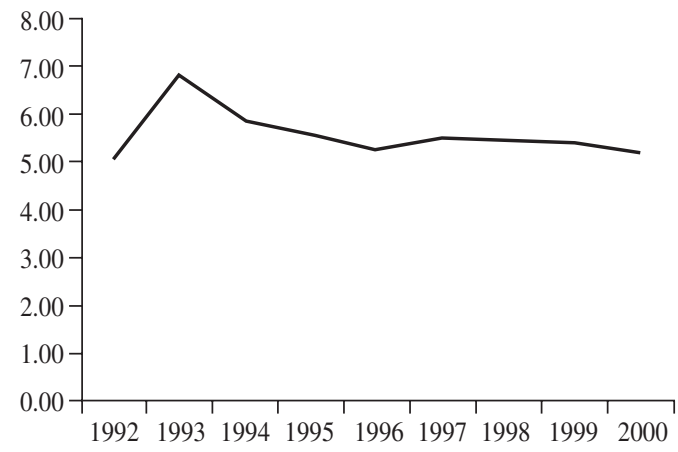

Gas

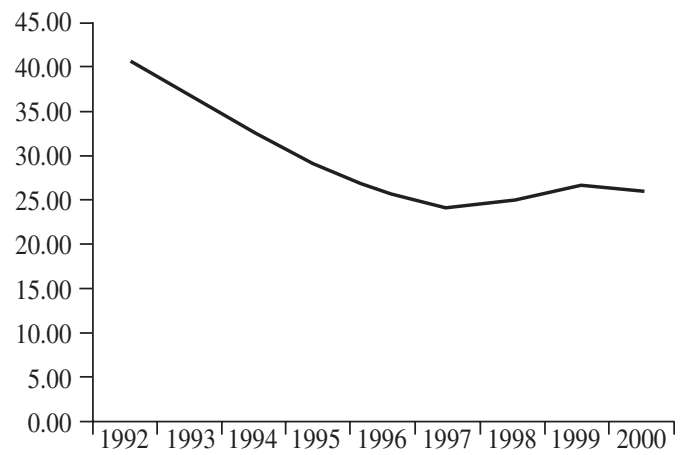

IPB

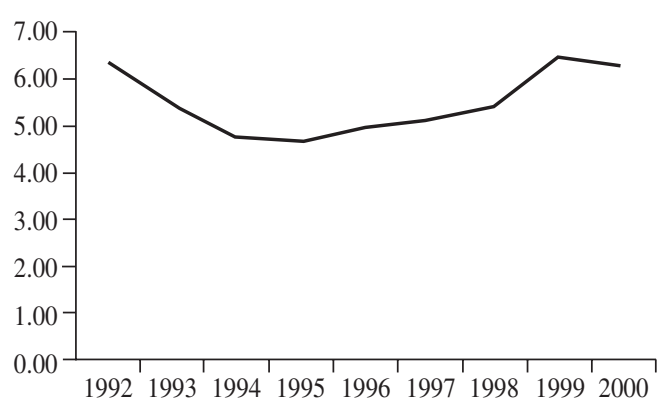

agrícolas aumentó con los inicios de la crisis en 1997, disminuyó en 1998 y volvió a subir en 1999. Los precios de los combustibles fueron más volátiles en 1998 y en 2000. Como resultado de lo anterior, el índice sin combustibles fue más volátil en 1997 y en 1999, mientras que el índice general lo fue solamente en 1999.

Para fines ilustrativos se presentan los otros estadísticos que están relacionados con las direcciones de
Agrícola

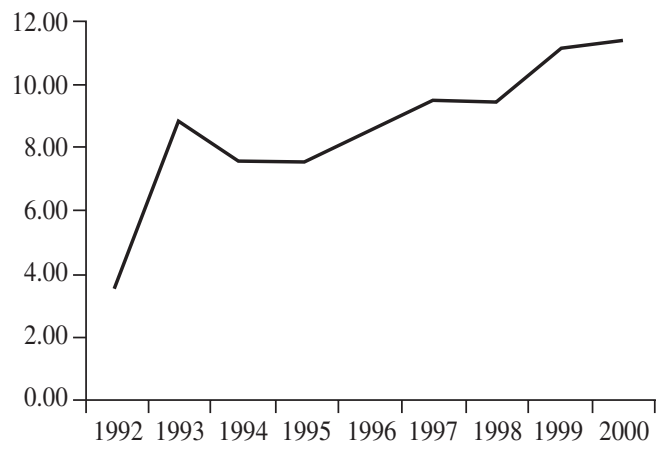

Petróleo

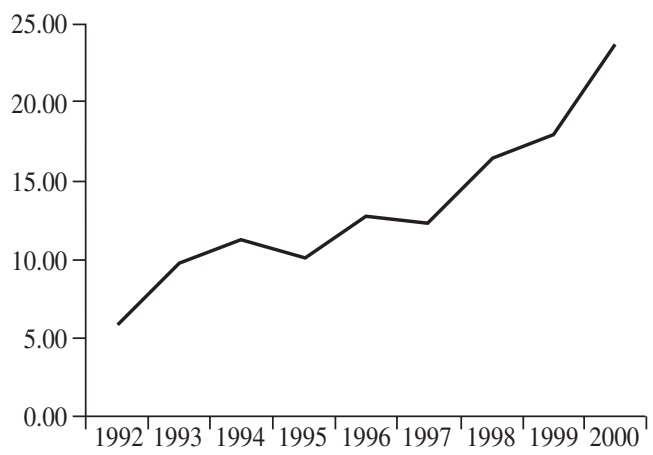

IPB s/c

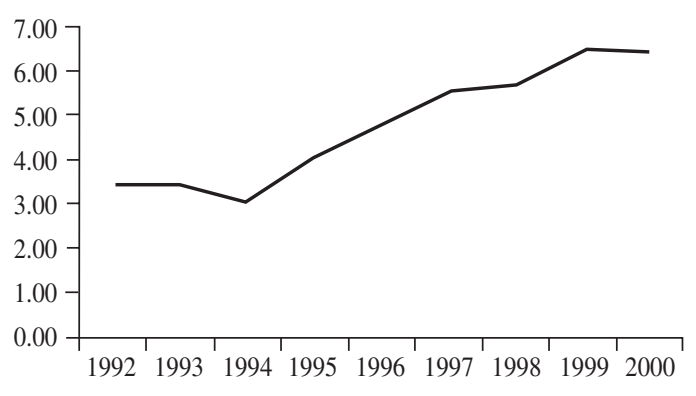

la dispersión de los datos de las series de precios respecto a su centro y que completan la descripción de las distribuciones de frecuencia. Estas características se refieren a asimetría y a curtosis o apuntamiento. El índice general de precios presenta una distribución de frecuencia con una asimetría negativa (la moda, el valor que más se repite, supera a la media), la distribución tiene una ramificación más extendida hacia la 
izquierda o hacia valores pequeños de la variable, mientras que el índice que excluye los combustibles presenta una asimetría positiva (la moda es menor que la media), es decir, la distribución tiene una ramificación más extendida a la derecha. En su mayoría, los precios de los productos del sector minero tienen una asimetría negativa. La distribución de frecuencias de los precios de los productos básicos medidos a través del índice general y del índice sin combustibles presenta una distribución más aplanada (leptocúrtica). Sin embargo, los principales productos mineros, los del complejo de la soja, así como los combustibles, presentan un distribución de frecuencias más apuntada que la normal (platicúrtica), lo que significaría que los valores se concentran más alrededor del promedio.

En resumen, el índice general de precios de Bolivia no muestra una elevada volatilidad si se la compara con la encontrada para países en desarrollo (por ejemplo, en Reinhart y Wickham, 1994). Los precios de los metales son los menos volátiles y los precios de los combustibles los más volátiles. Si bien los precios de la agricultura tienen una volatilidad intermedia, la harina, el aceite de soja, el café, el azúcar y el algodón son los productos con precios más volátiles de la canasta boliviana de exportación. La crisis internacional aumentó la volatilidad de los precios en 1997 y nuevamente en 1999.

\section{Riesgo de cartera de la exportación de produc- tos básicos}

Para analizar si la estrategia implícita adoptada por el país de diversificar las exportaciones de productos básicos disminuyó el riesgo de la cartera de exportación, se calculan en primer lugar las matrices de las varianzas y covarianzas entre los índices de precios de los productos y de los sectores y, en segundo lugar, el riesgo de la cartera, utilizando para ello la siguiente fórmula:

$$
R=w_{1}^{2} s_{1}^{2}+w_{1} w_{2} s_{12}+\ldots+w_{1} w_{n} s_{1 n}+\ldots+w_{n-1} w_{n} s_{n-1 n}+w_{n}{ }^{2} s_{n}^{2}
$$

donde:

$R=$ riesgo de la cartera

$W_{\mathrm{i}}=\mathrm{V}_{\mathrm{i}} / \mathrm{V}_{\mathrm{t}}=$ valor del sector o producto $i /$ valor total de la cartera

$S_{i}=$ varianza del índice de precios del sector o del producto $i$

$S_{i j}=$ covarianza de los índices de precios de los sectores y productos $i$ y $j$

$n=$ número de sectores o productos.
Del análisis de la matriz de varianzas y covarianzas se desprende que si las covarianzas son negativas el riesgo disminuye, puesto que las fluctuaciones de los precios de los productos se compensan entre sí, es decir, hay coeficientes de correlación negativos que permiten disminuir el riesgo de la cartera.

En el caso boliviano, para el conjunto de la canasta exportadora de productos básicos el riesgo total es positivo (40.67), al igual que a nivel de sectores (38.8), respecto a un índice de 100 (cuadro 8). Este indicador nos mostraría que pese a presentar una estructura diversificada por sectores de exportación de productos básicos no le ha significado diversificar el riesgo.

Para determinar cuánto contribuye la incorporación de un nuevo sector a aumentar o minimizar el riesgo, se presentan los resultados de incorporar a una canasta ya existente, como la de los metales, nuevos productos que serían del complejo de la soja (cuadro 9). Se observa que el riesgo inicial de 30.11 en el sector minero sube a un riesgo total de 35.49 al incorporar dicho complejo.

Sin embargo, es en el ámbito de los precios de los productos específicos donde el análisis de las covarianzas nos muestra la presencia de compensaciones, según los siguientes resultados:

- Existe un total de 31 pares de productos con covarianzas negativas, de un total de 78 pares de productos, es decir, hay un $40 \%$ de compensaciones intrasectoriales e intersectoriales.

- Las compensaciones al interior de los sectores son mayores en el sector minero, con tres pares de productos de un total de seis, como en los casos del zinc con el oro (-0.66), el zinc con la plata $(-0.58)$ y el oro con la plata (-0.30). Esto último significa que, contrariamente a lo esperado, dentro

CUADRO 8

Bolivia: Matriz sectorial de varianzas y covarianzas

(Indices de precios de los productos básicos: $1996=100)$

\begin{tabular}{lccc}
\hline & Metales & $\begin{array}{c}\text { Sector } \\
\text { agrícola }\end{array}$ & Combustibles \\
\hline Metales & 5.91 & & \\
Sector agrícola & 3.24 & 16.26 & \\
Combustibles & 2.12 & 3.50 & 7.78 \\
\hline Sumatoria ponderada de varianzas & & 29.95 \\
Sumatoria ponderada de covarianzas & & 8.87 \\
Riesgo total & & 38.82 \\
\hline
\end{tabular}

Fuente: Elaboración propia con datos del Banco Central de Bolivia. 
CUADRO 9

Bolivia: Cartera de metales y complejo de la soja

A. Escenario inicial: considerando portafolio de metales

\begin{tabular}{lrrrr}
\hline & Zinc & Oro & Estaño & Plata \\
\hline Zinc & 20.55 & & & \\
Oro & -3.12 & 7.32 & & \\
Estaño & 1.97 & 0.18 & 2.33 & \\
Plata & -2.73 & -1.42 & 0.22 & 4.80 \\
\hline Sumatoria ponderada de varianzas & & 35.00 \\
Sumatoria ponderada de covarianzas & & -4.89 \\
Riesgo total & & 30.11 \\
\hline
\end{tabular}

B. Escenario final: considerando portafolio de metales, añadiendo el complejo de la soja

\begin{tabular}{lrrrrrrr}
\hline & Zinc & Oro & Estaño & Plata & Soja & Harina & Aceite \\
\hline Zinc & 9.35 & & & & & & \\
Oro & -1.42 & 3.33 & & & & & \\
Estaño & 0.90 & 0.08 & 1.06 & & & & \\
Plata & -1.24 & -0.64 & 0.10 & 2.18 & & & \\
Soja & 0.77 & 0.83 & -0.24 & -0.51 & 1.85 & & \\
Harina & 1.95 & 2.49 & 0.12 & -1.02 & 2.89 & 7.94 & \\
Aceite & 0.21 & 1.06 & 0.09 & -1.14 & 0.68 & 0.63 & 3.18 \\
\hline Sumatoria ponderada de varianzas & & & & 28.90 \\
Sumatoria ponderada de covarianzas & & & & 6.59 \\
Riesgo total &
\end{tabular}

Fuente: Elaboración propia con datos del Banco Central de Bolivia.

del sector de los metales preciosos las fluctuaciones de precios se compensan. En el sector agrícola la compensación es de $30 \%$ (siete de 22 pares de productos), resaltando el hecho de que no hay compensación al interior del complejo de la soja. Las compensaciones se dan entre la madera y este complejo, entre el café y el azúcar (-0.11) y entre la madera y el café (-0.75).

- Hay significativas compensaciones intersectoriales, 21 de un total de 31 pares de productos con covarianzas negativas. Entre el sector minero y el agrícola resaltan las covarianzas negativas de los precios de la plata con los productos agrícolas, excepto la madera, y las compensaciones de los precios del zinc con los de las maderas, el algodón y el azúcar. Entre el sector agrícola y el minero resaltan las compensaciones de la soja con la plata y el estaño, el azúcar con los productos mineros (salvo el oro) y la madera con el zinc y el oro.

- Entre el sector de los combustibles y la minería hay compensaciones de la plata con el gas y el petróleo, y del oro con el petróleo. Entre el sector de los combustibles y el agrícola se observa que el petróleo presenta covarianzas negativas con todos los productos, excepto el algodón. En el caso del gas, que será el principal producto de exportación, sus precios se mueven en distinta dirección que los de la plata, las maderas y el café, destacándose que no se compensa con el complejo de la soja. Sin embargo, los precios del gas reflejaron los precios decrecientes del contrato con Argentina, por lo que su comportamiento en el futuro podría ser similar al del petróleo, que presenta movimientos compensados con la mayoría de los productos.

En síntesis, a nivel de sectores no existe una disminución del riesgo, puesto que los precios se mueven en la misma dirección. Sin embargo, en el ámbito de los productos se observan importantes compensaciones por la dirección en que se mueven los precios dentro de un mismo sector y en productos de distintos sectores. Resalta el mayor número de compensaciones que se dan en la canasta de exportación del sector minero, especialmente en los metales preciosos. A nivel intersectorial, destacan las compensaciones de los precios de la plata con los de los combustibles y de la mayoría de los productos agrícolas, así como de los precios de la soja con los de la plata, el estaño y el petróleo. El precio del gas sólo se compensa con los de muy pocos productos.

\section{VI}

\section{Conclusiones y recomendaciones}

\section{Conclusiones}

La literatura empírica y teórica reciente no ha asignado a los shocks en los precios de los productos bási- cos la misma importancia que a las crisis financieras, aunque ha vuelto a dar cierta importancia al tema de la persistencia de las perturbaciones de precios. Se ha encontrado evidencia empírica de que éstas son per- 
sistentes, y de que la duración de la fase de declinación de los precios excede a la duración de la fase de auge. Es decir, existen elementos que abonan la existencia de una tendencia secular a la caída de los precios de los productos básicos. Sin embargo, existe también alguna evidencia de que no sería acertada la percepción de caídas generalizadas de precios de estos productos.

El bajo desempeño de las exportaciones bolivianas no está en línea con el dinamismo de las exportaciones mundiales, fuertemente concentradas en las manufacturas. Esto sucede porque Bolivia depende altamente de las exportaciones de productos básicos (84\% de las exportaciones totales en 1999), cuyos precios declinaron en forma significativa en el decenio de 1990, provocando un fuerte deterioro de la relación de precios del intercambio. No obstante, en la composición de las exportaciones bolivianas no predominan unos pocos productos, como sucede en la mayoría de los países en desarrollo, ni hay dependencia de un sector en particular. Esta característica debiera haber permitido una disminución de la vulnerabilidad externa del país. Sin embargo, los resultados del trabajo muestran que no se ha minimizado el riesgo, atenuado los ciclos ni disminuido la volatilidad de los precios de exportación.

Los precios de los productos básicos de exportación de Bolivia exhiben un comportamiento cíclico con tendencia decreciente y con una duración de la fase de auge similar a la de la fase de declinación. La magnitud de la caída de los precios en la fase de descenso, a partir de la crisis asiática, fue ligeramente superior a la magnitud del alza en la fase de bonanza. Si se suaviza la tendencia, la fase de contracción dura mucho más que la de recuperación. La perturbación de los precios de corto plazo empezó a sentirse con más fuerza en Bolivia a partir de mayo de 1998, cuando los precios observados llegaron a ser inferiores a su tendencia, pese a que la caída de los precios se había iniciado en junio de 1997.

Los shocks permanentes ayudan a explicar la varianza de los precios mensuales. Sin embargo, existe un componente permanente en los shocks de los precios en Bolivia, aunque menor que el observado para los países en desarrollo; a nivel sectorial este componente es mayor, aunque de poca persistencia, en los metales. Por lo tanto, la reciente caída de precios no ha tendido a disiparse rápidamente. La importancia relativa de las perturbaciones permanentes es mayor en los precios de los metales, ya que el $69 \%$ de la varianza mensual de éstos se debe al componente per- manente, mientras que en los sectores agrícola y de combustibles la cifra es de $25 \%$ aproximadamente y en los índices generales de precios, incluidos y excluidos los combustibles, de alrededor de $30 \%$. El componente permanente de los precios de los metales exhibe un bajo grado de persistencia.

En el caso boliviano, a diferencia de lo encontrado para los países en desarrollo, se halló un alto grado de concordancia a nivel sectorial, lo que indicaría que la diversificación de las exportaciones de productos básicos no ha permitido atenuar los efectos del ciclo de los precios, de modo que esa diversificación no ha sido anticíclica. Sin embargo, a nivel de productos se ha encontrado que un tercio de las exportaciones corresponde a productos con precios contracíclicos, como el de la plata y el estaño (que representaron $13.1 \%$ de las exportaciones en 1996) respecto al de la soja y la harina (14.3\%) y el de la plata con relación al del gas (que representó el 8\%).

El índice general no muestra una volatilidad elevada, si se la compara con la que señalan otros estudios ya citados para los países en desarrollo. Los precios de los metales son los menos volátiles y los precios de los combustibles los más volátiles. Los precios de la agricultura, si bien tienen una volatilidad intermedia a nivel de productos específicos como la harina, el aceite de soja, el café, el azúcar y el algodón, estarían entre los más volátiles de la canasta boliviana de exportación. La crisis internacional aumentó la volatilidad de los precios en 1997 y lo hizo nuevamente en 1999.

Con la aplicación del método de riesgo de cartera a la canasta de exportación de Bolivia, no utilizado en trabajos similares para los países en desarrollo mencionados en el marco teórico, se encuentra que la incorporación de un nuevo sector exportador de productos básicos a la cartera exportadora, como el sector de la soja, no ha disminuido el riesgo total. Sin embargo, a nivel de los productos de la canasta de exportaciones se ha observado un porcentaje significativo (40\%) de compensaciones intrasectoriales e intersectoriales. Dentro de los sectores son mayores las compensaciones en el sector minero y entre los metales preciosos. En el sector agrícola, la compensación es de un $30 \%$ y no se encuentran compensaciones al interior del complejo de la soja.

Hay significativas compensaciones entre el sector minero y el agrícola. Resaltan las covarianzas negativas de los precios de la plata con los de los productos agrícolas, excepto la madera, y las compensaciones del precio de la soja con los de la plata y el 
estaño. Entre el sector de los combustibles y la minería se observan compensaciones de los precios de la plata con los del gas y el petróleo, y del oro con el petróleo. Entre el sector de los combustibles y el agrícola, se observa que el petróleo exhibe covarianzas negativas con todos los productos agrícolas, salvo el algodón, y que el gas presenta pocas compensaciones.

Las perspectivas del sector exportador están centradas en la minería de la plata y en la exportación del gas; se verificó que ambos productos tienen un comportamiento complementario, lo que atenúa el impacto de shocks adversos. Por un lado, mientras el precio de la plata es poco volátil el del gas es muy volátil. Por otro lado, los precios de la plata y el gas muestran movimientos en distinta dirección, por lo que ambos productos contribuyen a disminuir el riesgo y, por ser anticíclicos, ayudan a atenuar la fase del ciclo.

\section{Recomendaciones de política}

No es aconsejable que el país persista en una estrategia basada principalmente en la exportación y diversificación de productos básicos, que en la década de 1990 no le ha permitido minimizar el riesgo, atenuar los ciclos, disminuir la volatilidad de los precios de exportación ni aumentar los ingresos reales de exportación.

La evidencia empírica ha mostrado que Bolivia necesita complementar su estrategia de diversificación de exportaciones de productos básicos con una estrategia explícita de desarrollo de las exportaciones de manufacturas que, a diferencia de la política neutra aplicada hasta ahora, incluya políticas selectivas de fomento de la producción y las exportaciones, para ayudar así a disminuir la vulnerabilidad externa ante perturbaciones externas adversas en los precios de los productos básicos. Esto quiere decir que se necesitan medidas de carácter estructural para disminuir la alta vulnerabilidad externa.

La política cambiaria debería tomar en cuenta, entre los diversos indicadores que utiliza, el comportamiento de los precios de los productos básicos y en especial la relación de precios del intercambio. Tendría que contribuir a atenuar las perturbaciones adversas, puesto que ellas tienen efectos negativos en el nivel de las exportaciones y de la actividad económica.

La presencia de shocks permanentes minimiza los efectos de las políticas de estabilización de precios de los productos básicos que recomienda el FMI. Pero el hecho de que exista un importante componente transitorio hace aconsejable que Bolivia aplique medidas transitorias o de corto plazo, como la facilitación de recursos financieros ante caídas de los ingresos de exportación en el marco de los programas de asistencia financiera del FMI y la aplicación de fondos de estabilización para algún producto estratégico — la soja, por ejemplo_- como hace Chile con el cobre.
Bielschowsky, R. (1998): Evolución de las ideas de la CEPAL, Revista de la CEPAL, Número extraordinario, LC/G.2037-P, Santiago de Chile, Comisión Económica para América Latina y el Caribe (CEPAL), octubre.

Borensztein, E., M. Khan y otros (1994): The Behavior of Non-Oil Commodity Prices, Occasional paper, $\mathrm{N}^{\circ}$ 112, Washington, D.C., Fondo Monetario Internacional, agosto.

Cashin, P., H. Liang y C. McDermott (1999): How Persistent Are Shocks to World Commodity Prices?, IMF working paper, $\mathrm{N}^{\circ} 80$, Washington, D.C., Fondo Monetario Internacional, junio.

Cashin, P., J. McDermott y A. Scott (1999a): Booms and Slumps in World Commodity Prices, IMF working paper, № 155 , Washington, D.C., Fondo Monetario Internacional, noviembre. (1999b): The Myth of Comoving Commodity Prices, IMF working paper, $\mathrm{N}^{\circ} 169$, Washington, D.C., Fondo Monetario Internacional, diciembre.

Cashin, P. y C. Patillo (2000): Terms of Trade Shocks in Africa: Are They Short-Lived or Long-Lived?, IMF working paper, $\mathrm{N}^{\circ}$ 72, Washington, D.C., Fondo Monetario Internacional, abril.

CEPAL (1969): El pensamiento de la CEPAL, Santiago de Chile, Editorial Universitaria.

Dehn, J. (2000a): The Effects on Growth of Commodity Price Uncertainty and Shocks, Policy research working paper, $\mathrm{N}^{\circ} 2455$, Washington, D.C., Banco Mundial. (2000b): Commodity Price Uncertainty in Developing Countries, Policy research working paper, $\mathrm{N}^{\circ} 2426$, Washington, D.C., Banco Mundial.

Hodrick, R. y E. Prescott (1997): Post-war U.S. business cycles: An empirical investigation, Journal of Money, Credit and Banking, vol. 29, $\mathrm{N}^{\circ} 1$, Columbus, Ohio, Ohio State University.

Krueger, A. (1984): Trade policies in developing countries, en W.Jones y P.B. Kenen, Handbook of International Economics, vol. I, Amsterdam, Países Bajos, North-Holland.

Larson, D., P. Varangis y N. Yabuki (1998): Commodity Risk Management and Development, Washington, D.C., Banco Mundial.

Lewis, W. A. (1960): Desarrollo económico con oferta ilimitada de mano de obra, El trimestre económico, vol. XXVII (4), $\mathrm{N}^{\circ} 108$, México, D.F., Fondo de Cultura Económica.

Moya, R. (1991): Estadística descriptiva, Lima, Editorial San Marcos.

Núñez del Prado, A. (1969): Estadística básica para planificación, Cuadernos del ILPES, serie I, $\mathrm{N}^{\circ}$ 5, Santiago de Chile, Instituto Latinoamericano y del Caribe de Planificación Económica y Social (ILPES).

OMC (Organización Mundial de Comercio) (2000): Informe anual 2000, Ginebra.

Prebisch, R. (1949): El desarrollo económico de América Latina y algunos de sus principales problemas, Santiago de Chile, CEPAL. Reproducido en Boletín económico de América Latina, vol. 7, $\mathrm{N}^{\circ}$ 1, Santiago de Chile, CEPAL, 1962. 
(1952): Problemas teóricos y prácticos del crecimiento económico, México, D.F., CEPAL. Reproducido en CEPAL, Cincuenta años de pensamiento en la CEPAL. Textos seleccionados, vol. 1, Santiago de Chile, 1998.

Reinhart, C. y P. Wickham (1994): Commodity prices: Cyclical weakness or secular decline?, Staff Papers, vol. 41, No 2 , Washington, D.C., Fondo Monetario Internacional, junio.

Ros, J. (1998): Relación del intercambio y desarrollo desigual, Revista de la CEPAL, Número extraordinario, LC/G.2037-P, Santiago de Chile, CEPAL, octubre.
Singer, H. W. (1950): The distribution of gains between investing and borrowing countries, The American Economic Review, vol. $40, \mathrm{~N}^{\mathrm{o}} 2$, Nashville, Tennessee, American Economic Association.

Sprout, R. (1992): El pensamiento de Prebisch, Revista de la CEPAL, $\mathrm{N}^{\circ}$ 46, LC/G.1717-P, Santiago de Chile, CEPAL.

Varangis, P., T. Akiyama y D. Mitchell (1995): Managing Commodity Booms and Busts, Washington, D.C., Banco Mundial. 